\title{
PREVENTION IN DENTISTRY AS VIEWED BY A DENTAL HEALTH EDUCATOR*
}

\author{
By Shirley R. Pyke, RDH, BS(Ed), MPH**
}

A dental health educator, with considerable experience in her attempts to
promote improved oral health behavior, takes a hard look at the programs
designed to teach continuing removal of dental plaque to school children.

The concept of prevention, in spite of recent vigorous emphasis, is not new to the practice of dentistry; for many years it has been a basic part of the practice of dental public health. The early investigations of those such as $\mathrm{McKay}^{12}$ and others in detecting an elusive fluoride ion and, the developments by Jay and his associates ${ }^{7}$ in the dietary control of dental caries are just two of the pioneering activities directed toward the prevention of dental disease.

Today's burgeoning emphasis of another preventive effort - the continuous removal of plaque to reduce carious lesions and sustain ginigval health - has gained such widespread momentum that dentists and their personnel find themselves in the midst of something called the "Prevention Movement." No attempt will be made to define this movement because the term has meanings which vary in different groups and appear to depend on the practitioners' present orientation, their past experience, their desire to be scientific, or their motivation to practice economically.

To the educator in dental public health, each new preventive activity poses the question: "To what extent will this current interest and activity actually influence the public's oral health for the better, by motivating change in behavior?" The educator soon recognizes that the current movement relies on educational technics for influencing people to perform certain procedures individually, regularly, and in their homes. The ritual has not been practiced long enough in a scientifically ordered situation to demonstrate improved behavioral changes over a long sustained period. The health educator, hence, must ask another question: "What is the potential of this movement in the practice of public health?"

This paper, then, will discuss briefly three of the programs reported in the literature to date, and examine each of them in the light of the five evaluative criteria developed by the American Public Health Association's Committee on Evaluation and Standards ${ }^{1}$ :

1. Appropriateness. This criterion demands the determination of the extent to which programs are directed toward a significant health problem of high priority.

2. Adequacy. Criterion No. 2 demands that one learn the proportion of the total problem that the program is expected to solve.

3. Effectiveness. The third criterion demands that the reader ask, "To what extent have the preestablished objectives been attained as a result of the program's activity?"

4. Efficiency. The fourth criterion, so pertinent in the practice of public health, is the cost in resources of attaining the objectives.

5. Side Effects. Finally, a scientifically oriented examiner must determine the unexpected results of the program's activity.

* Presented to the Dental Health Section of the American Public Health Association at Atlantic City, November 13, 1972.

**Assistant Professor of Dental Public Health, School of Public Healch, University of Michigan, Ann Arbor, 48104 


\section{The Literature on Preventive Programs in Action}

At this point, three programs have been found for review in the short period permitted for this paper. One is a program in the Armed Forces, one is the program in Cleveland reported by Clark and Fintz, and the third is the "Toothkeeper" popularized by Masters.

\section{The U.S. Army}

Cassidy and Barnes $(1972)^{3}$ reported a program, carried out at an Army Post, which included three major areas of emphasis: (1) preventive treatment consisting of the use of fluorides, institution of protective mouth-guards, practice of measures to interfere with certain types of developing malocclusion, and treatment of any conditions likely to result in an emergency while the serviceman is on active duty; (2) educating to gain motivation of preventive measures with the aid of audiovisual presentation, sessions in small groups, and in-service education of the staff; and (3) research on prevention which included clinical and evaluative studies.

The program of treatment emphasized anticariogenic therapy. A technic for selfapplied prophylaxis, using a nine percent solution of stannous fluoride-zirconium-silicate paste, was developed when the dental officers realized that 17,000 chairside treatments, rendered annually, would have little effect on a population of 65,000 troops. Videotapes, containing educational information and instructions for the semiannual selfapplication of the paste were shown in an oral hygicne clinic specially equiped with 12 television monitors. In this clinic a total of 220 persons could be instructed simultaneously. With the aid of this method, the number of self-applied prophylaxes increased to 65,000 in 12 months. Military personnel accounted for 57,000 and their dependent children for 8,000 treatments.

\section{The Cleveland Model}

Clark and Fintz (1972) ${ }^{6}$ reported a program designated as the "Cleveland Model," the purpose of which was (1) to provide sixth-grade students with an understanding of the development of carious lesions and periodontal disease; (2) to demonstrate how these diseases may be prevented; and (3) to maintain participation by the students under direct supervision until they were prepared to demonstrate the technic and teach proper bchavioral patterns to the entire family. These objectives were expected to be attained through an intensive program in which classroom teachers, students, parents, and mass media all participated. The major thrust of the program was "staining, flossing and brushing" with the addition of some dietary counseling. Unique in this program was the objective of developing sixth-graders as the teachers of other members of the family.

In Cleveland's project, a group of sixth-grade teachers was instructed in preventive dental technics and practices for oral health during a session one-day long. A dental health consultant, who might be a dentist, dental hygienist, or school nurse, provided the initial instruction and the periodic supervision for the classroom teachers throughout the school year. The teacher then was expected to transfer to the classtoom the technics and information that she has acquired. During the first week of this phase of the program she directed the instruction required in the classroom for one hour per day on five consecutive days, in order to teach the course, which included the use of a phase microscope, films, transparencies, lectures, and demonstrations. During the second week, reinforcement of the technic was supervised and required from 10 to 30 minutes each day for five consecutive days. For the remaining part of the school year, self-reinforcement by students was encouraged. The pairing of students for shared inspections stimulated competition among the students for approval by peers. Each student reccives constant encouragement to transfer to other members of the family the preventive technics and information that he has acquired. 


\section{The Toothkeeper}

The "Toothkeeper Program," described by Masters (1972), ${ }^{9}$ was similar to the program reported by Clark and Fintz in that both programs were designed for use in schools and both depended on the classroom teacher to educate the student in the procedures for gaining oral health. The Toothkeeper comes in a package designed for grades kindergarten through six and is available to school systems through a commercial dental supplier. The package includes two films in color, a model of a quadrant of the mouth, the kit containing disclosing tablets, toothbrushes, dental floss, mirrors, and appropriate guides for parents, teachers, school administrators, and dental consultants.

Among the concepts which served as the guides for the development of the program were $^{10}$ (1) an effective program of prevention must eliminate the cause and not just the treatment of the results of disease, and it must emphasize the development of skill and habits in the technic for removing plaque and in the proper selection of food; and (2) with the dentist's role in prevention sharply limited, the classroom teacher, trained as a dental health educator, occupies the most effective position for altering the oral health of the young. Master's program, hence, relies on specific instructions carried out systematically and repetitiously. The program, developed by Masters, utilizes instruction during a workshop for teachers on the performance of the specific technics for brushing and flossing and the accompanying accurate oral health information from a dental consultant. The consultant usually is a member of the local dental society who has been taught the specific technics by a representative of "Toothkeeper." Participating teachers are expected to carry out the program for 16 consecutive weeks in their classrooms. The frequency with which students participate in the program depends upon the enthusiasm of the teacher. The philosophy of "Toothkeeper" is expressed in its motto, "Remember: Dentists can't! Parents can't! Teachers can!"

Now the examination of the three programs appears in order to determine where they rate for appropriateness, adequacy, effectiveness, efficiency, and side effects.

Appropriateness. The data, reported by the U.S. Public Health Service, Center for Health Statistics in 1970 and $1971,{ }^{15,16}$ indicate that 98 percent of the population in this country experiences some form of oral disease, that eight out of 10 children have dental disease by the age of nine, and that only 40 percent of the population ever go to the dentist. Projections of dental manpower indicate that there never will be enough dental personnel to meet the accumulated oral needs in the United States during the balance of the century. ${ }^{14}$ The federal government, hence, has predicted a crisis in dental manpower and has made grants available for experimental training in prevention as well as research to gain better methods of prevention. Because oral disease affects so many people, and so little progress has been made in preventing such disease, it must be accepted as a significant health problem of high priority. Each program described is, in its own way, trying to reduce and eventually prevent oral disease. The extent to which the programs are directed to the problem which they attempt to solve still remains to be analyzed and evaluated before scientific data to defend them can be made available.

Adequacy. If adequacy pertains to the proportion of the total problem which a program is expected to solve then a careful examination of the scope of each program must be undertaken. The Army's program is available to military personnel and their dependents only. One has to be stationed at installations where such programs are in effect, and be within the priority assigned to those persons 25 years of age and under. Excluded from the self-administered prophylactic program are those military personnel and dependents stationed at installations where such programs are not in effect and, of course, civilians of all ages.

Cleveland's Model, included approximately 300 sixth-grade parochial school children during a pilot-program of 14 months. The program was designed for use in the fifth, 
sixth. and seventh grades. The guide for the program, A Manual of Dental Health, ${ }^{4}$ was utilized which claimed that the material and methods for teaching were too sophisticated for the lower grades, and that interest probably would wane if continued beyond the seventh grade. By designing a program specifically for the fifth, sixth and seventh grades, all other grades are excluded from consideration. The intent of the program designed, it should be kept in mind, was that the children exposed to the activity would transfer to their families the knowledge and technic to which they were exposed in the program at school.

The Toothkeeper was designed specifically for use in grades kindergarten through six. The rationale for beginning instruction in kindergarten through grade two, before efficient and stabilized manual dexterity becomes established, is important because it includes the years when habitual behavior is being developed. By virtue of the program designed, it excludes preschoolers, those beyond the sixth grade, and the family. Another exclusive factor of the Toothkeeper is that it is distributed commercially and requires considerable financial resources to enable participation by a school.

As one checks back on the appropriateness of the programs discussed, he is permitted to conclude that all of them tend to exclude a large segment of the population which they should serve, although oral disease excludes none.

Effectiveness. Preestablished objectives were not stated as such, hence, one has to note what each program emphasizes. The Army's program reported that a long-range evaluation of its activities was impossible because of the transient population which it served. From the one controlled study reported, one learns that observation of the educational segment of the video-tapes showed a statistically significant improvement of 20 percent in performing technics. ${ }^{3}$ No data were presented on the effect obtained in the control of oral disease as a result of the program.

A preliminary report ${ }^{5}$ from Cleveland's Model revealed, at the end of eight months, that the scores for Personal Hygiene Performance ${ }^{13}$ in the group studied were significantly lower than they were at the beginning. The controls, who received only the lecture and toothbrushing-kits, without the instruction and weekly reinforcement, showed slightly higher, but not statistically significant higher PHP scores than they did at the beginning of the study. At the end of 14 months, six months after the motivational exercises were terminated, the group studied demonstrated relatively clean mouths and the controls demonstrated slightly lower PHP scores than they did at the end of the eight months. The findings after 14 months for the group studied suggests to Clark and Fintz $\mathrm{s}^{5}$ that "good oral habits were maintained once soundly established." The children in the study are being followed presently to determine whether the reported reduction in PHP scores exhibits any relationship to caries-activity.

Preliminary data have been reported from a 15-week experience with Toothkeeper in the Texarkana school-system which included 5,000 Texan children in grades one through six. ${ }^{11}$ One examiner, using Loe's index for gingival inflammation ${ }^{8}$ examined a sample of 538 children. This index was selected because (1) it correlates closely with the scores for plaque, and (2) it relates to gingivitis. The data as interpreted by this examiner, revealed a three-fold improvement in gingival health. Inasmuch as the study did not include a group of controls, the validity of this finding has been questioned. All of the children in grades one through six in the school-system participated in the group studied. A survey conducted following the program by questionnaire revealed a positive response by teachers in favor of continuing to serve as dental health educators; a positive response in favor of the program from students in the sixth grade; and strong administrative support for continuing the program.

Efficiency. The cost of the program in terms of resources - both manpower and money - should provide implications for a program of public health. The Army's program was 
carried out mainly through the use of video-tape as an educational and instructional tool in the oral hygiene clinic equipped with 12 television monitors. Army personnel (number not reported) were present at all times during the self-treatment. Children, attending the Post's school for dependents, gained their self-application of treatment in their schools under the supervision of dentists and dental hygienists. The manpower necessary for implementing this program was readily available because all of the personnel were military and functioned in the program as a part of their regular duty but their actual cost could not be ascertained from the report. Both the development of the video-tape and the purchase and installation of the 12 television monitors in the oral hygiene clinic were provided by the Army and the cost also was not reported. No data, in fact, were reported on the total cost of the program. Inasmuch as it appears that the costs might be minimal, when distributed proportionately among the 65,000 treatments rendered, an estimate of costs in terms of a civilian program would be interesting to learn.

An analysis of the efficiency of Cleveland's Model reveals that the costliest single item in the program would be manpower. The employment of two dental consultants who instruct the teachers and make two supervisory visits to each teacher during the year is an annual expenditure born by the school-system. The cost in teachers' salaries allocated for the time devoted to the program was not reported. The dental consultants' salaries were stated to be $\$ 5,000$ annually for each consultant. The equipment required for operating the program would require an initial expenditure and a small annual amount for maintenance. The cost of supplies per child computed over a period of three years has been estimated to total $\$ 2.22$ or $\$ 0.74$ per child per year. The summary ${ }^{2}$ indicates that the costs per child which include capital outlay, without costs for instruction by teachers, for the administration of the program, and for the cost of supplies during three years were reported to range from $\$ 5.39$ for 22 classrooms with 15 pupils per class to $\$ 3.38$ for 400 classrooms with 30 pupils per class.

The efficiency of Toothkeeper apparently is dependent upon the number of children enrolled in the school-system for which the "package" is purchased. In addition to the 25-minute film which is a part of the package, a 10-minute film, which is a segment of the longer one, is suggested for every four classrooms. The shorter film is used for reinforcement and should be available readily for use according to the discretion of the classroom teacher. Since Toothkeeper relies on the local dental society to provide instruction and consultation to the teachers, no additional personnel are necessary. Once the initial package, including the films, has been purchased, the only other cost incurred is the cost of replacing supplies (disclosing tablets, toothbrushes, and floss) annually. The annual cost of the time devoted to the program by the teachers and the time donated by local dentists would have to be estimated for a true cost-analysis in a public health program. Such data have not been reported.

Side Effects. Finally, as one checks evaluation, step by step, one has to determine whether any unexpected results or side-effects exist in the three preventive programs described.

Cassidy and Barnes reported, as a result of their total preventive program that the dental officers assigned to that particular installation consistently developed an increased interest in a preventive type of practice. Whether they were reporting an impression or a factual survey was not indicated.

The enthusiasm and interest in dental health generated by Cleveland's Model was such that the Greater Cleveland Associated Foundation agreed to underwrite the cost of producing instructional materiais and films for the program to use.

Teachers who participated in Toothkeeper credited flossing of the model teeth for aiding the children in their development of manual dexterity in grades kindergarten through two. 
A side effect which might prove to be detrimental in all of the programs is the possibility that the participants may develop a false sense of security about their oral health and become disillusioned if, in spite of their preventive efforts, carious lesions or gingivitis develop in their mouths.

\section{Additional Discussion}

Three preventive programs now have been described, as reported in the literature, and have been examined according to the criteria for public health progtamming. Each of the programs has its own unique emphasis. The Army utilizes the self-administered prophylaxis; Cleveland's Model is designed to transfer knowledge and skill by child to the family; and the Toothkeeper includes the participation of the local dental society. All are concerned with reducing the prevalence of oral disease by inducing behavior which maintains oral health. Each program described is exclusive in that it is designed to serve a captive population with no provisions for those outside of its target save in Cleveland's Model. This program does emphasize transference to the home although the result has to be reported.

Each of the programs described requires a standard by which success or failure can be measured. The Army and Cleveland's Model relied on the results reported by examiners within their own systems. Toothkeeper, having been accepted by several school systems in the southern section of the United States, has to rely on results reported by a variety of examiners without benefit of calibration. The designers of the Toothkeeper, realizing the need for a uniform system of measuring the effects of participation in their program are considering the development of an index.

As pointed out earlier, there are certain costs associated with each of the programs described. The unanswered question is, "Do the results justify the total cost?" Unfortunately, the programs have not been in existence long enough for valid cost-benefit analyses and no attempts have been made to assess the associated costs accurately. This special preventive movement and its activities still seem to be in the experimental stages and some time will have to pass before anyone even can determine definitely that a decrease in oral disease occurs. Until a reduction in disease can be proven as a result of the movement and the period that the reduction maintains has been determined, an attempt to analyze the true cost-benefit of the activity is futile.

Proponents of the movement are justified in their argument that there must be a starting place and that a captive audience provided by schools is a logical beginning. Their argument that the youth of today are the parents of tomorrow who will instill the habits of personal oral hygiene in the next generation still has to be established. When the scientific method is applied in an oral health science that is studying prevention an accurate, scientific knowledge of the etiology of oral disease usually must be established. The identification of similar causative agents for the activity of dental caries and periodontal disease still may be somewhat controversial. Until this etiology is demonstrated beyond doubt, questions can be raised about the bases for expending the public's money and time on the preventive activities presented. Although research on causative agents still may be needed, the programs described may be successful in creating an awareness of oral health and disease in the limited populations which the programs serve.

\section{Summarizing}

Three preventive programs were described and examined for their potential as acceptable components of dental public health practice. An effort was made to examine each program on the basis of the criteria proposed for programming in public health practice. A question has been raised about the fundamental knowledge of etiology, about the duration of benefits in change of behavior, and about the true costs that have to be included in an analysis of cost-benefit. 


\section{Some Conclusions}

The examination and discussion presented in this paper appear to permit five conclusions:

(1) carefully planned, broad-based clinical study of the results of the various preventive programs currently promoted is needed promptly;

(2) scientific preventive programs should be based on valid epidemiological findings;

(3) longitudinal studies of behavioral changes should accompany each preventive program;

(4) the hidden costs should be assessed accurately for a cost-benefit analysis which would serve both the public and the private practice of dentistry; and

(5) preventive programs should be developed which are applicable to all segments of the population.

\section{Bibliography}

1. American Public Health Association, Committee on Evaluation and Standards. Glossary of evaluative terms in public health. Am. J. Pub. Health, 60:1546-52, Aug. 1970.

2. Berman, E. B. Cost-benefit analysis of selected preventive dentistry programs. Cleveland, Mitre Corporation, n.d. 9 p. duplicated.

3. Cassidy, J. E, and Barnes, G. P. Organization and operation of a military preventive dentistry program. Am. J. Pub. Health, 62:1072-6, Aug. 1972.

4. Clark, C. A. A manual of dental health; the complete guide for consultant, for teacher, for parent. Clevcland, Greater Cleveland Associated Foundation, c1972. V +63 p.

5. Clark, C. A., and Fintz, J. B. A plaque control program for six th grade children: a preliminary report. Cleveland, Department of Public Health, n.d. 5 p. +3 tables.

6. And the children shall lead them. Am. Soc. Preventive Dent. J., 1:27-9, July-Aug. 1971.

7. Jay, Philip, Beeuwkes, Adelia M., and Husbands, Julia. Dietary program for the control of dental caries. Ann Arbor, Overbeck, c1965. 30 p.

8. Loe, Harald. The ginigival index, the plaque index and the retention index systems. J. Periodont., 38:610-6, Nov.-Dec. 1967.

9. Masters, D. H. The role of the school dental consultant in a dental disease prevention program. Tex. Dent. J., 90:247, May 1972.

10. … The classroom teacher... effective dental health educator. J. School Health, 42:257-61, May 1972.

11. . Unpublished data, Aug. 7, 1972.

12. McKay, F. S. Mass control of dental caries through the use of domestic water supplies containing fluorine. Am. J. Pub. Health, 38:828-32, June 1948.

13. Podshadley, A. G., and Haley, J. V. A method for evaluating oral hygiene performance. Pub. Health Rep., 83:259-64, Mar. 1968.

14. Simmons, J. H. Summary of the Workshop on Dental Manpower, "Meeting the dental needs in the 1970's." Am. Col. Dent. J., 36:28-33, Jan. 1969.

15. U.S. Public Health Service, National Center for Health Statistics. Decayed, missing, and filled tecth among children; United States. Washington, Government Printing Office, $1971 . \mathrm{iii}+47 \mathrm{p}$.

16. __. Need for dental care among adults; United States - 1960-1962. Washington, Government Printing Office, 1970 . IV $+22 \mathrm{p}$.

17. Yeary, H. R. Report on dental disease prevention program to the President's Committee on Health Education. Houston, Den-Tal-Ez Manufacturing Corporation, 1972. 2 p. 